\section{Heterotopic Gastric Mucosa of the Proximal Esophagus: An Under recognized Entity}

\author{
Sarhani Asmae ${ }^{1 *}$, Paupard Thierry², Ghani Sara1', Salihoun Mouna \\ and Kabbaj Nawal'
}

${ }^{1}$ EFD-HGE, Universal Hospital Ibn Sina - UM5S, Rabat, Morocco

${ }^{2}$ Gastroenterology Department, Dunkirk Hospital center, France

\section{Abstract}

Heterotopic gastric mucosa (HGM) is an islet of gastric mucosa within the esophageal mucosa. These lesions can sit throughout the digestive tract and rarely in the upper third of the esophagus. The pathophysiology of HGM remains poorly understood.

Our study aims to estimate the prevalence of HGM, clinical signs, endoscopic, microscopic aspects and different epidemiological factors associated.

All patients from a single endoscopy center with HGM of the upper third of the esophagus were included over a 5-month evaluation period. All lesions seen in endoscopy were confirmed by histological analysis.

The prevalence was $1.3 \%$ with a clear male predominance. $80 \%$ of patients were symptomatic and received medical treatment, clinical evolution was good. No case of dysplasia was identified and no complication was observed.

Due to insufficient data in the evolutionary literature, the management of HGM remains debated and could resemble that of Barett's esophagus for monitoring and therapeutic management, particularly in the event of symptoms or dysplasia.

\section{More Information}

*Address for Correspondence: Sarhani Asmae, EFD-HGE, Universal Hospital Ibn Sina - UM5S, Rabat, Morocco, Tel: 00212648878660; Email: sarhani.asmae@gmail.com

Submitted: 22 January 2020

Approved: 04 February 2020

Published: 05 February 2020

How to cite this article: Asmae S, Thierry $P$, Sara G, Mouna S, Nawal K. Heterotopic Gastric Mucosa of the Proximal Esophagus: An Under recognized Entity. Ann Clin Gastroenterol Hepatol. 2020; 4: 001-005.

DOI: dx.doi.org/10.29328/journal.acgh.1001014

Copyright: (c) 2020 Asmae S, et al. This is an open access article distributed under the Creative Commons Attribution License, which permits unrestricted use, distribution, and reproduction in any medium, provided the original work is properly cited.

Keywords: Heterotopic gastric mucosa; Proximal esophagus

\section{Check for updates}

OPEN ACCESS

\section{Introduction}

Heterotopic gastric mucosa (HGM), or Inlet Patch, is an island of gastric mucosa within the esophageal mucosa. These foci can sit all along the digestive tract but rarely in the cervical esophagus.

The pathogenesis of HGM in the cervical esophagus remains unclear. It looks different from Barett's esophagus. Two hypotheses exist, but the second is most restrained: Pathology acquired in association with gastroesophageal reflux as in Barett's esophagus or congenital malformation formed early in the course of embryogenesis.

The HGM is often by chance. Its prevalence varies between $0.1 \%$ and $13.8 \%$.

The main of this work is to study the prevalence of HGM, clinical signs, endoscopic and microscopic aspects as well as the various associated epidemiological factors from a monocentric series. Our results are discussed in light of the literature.

\section{Patients and methods}

This is a descriptive study carried out in a digestive endoscopy center which collected 10 cases of HGM of the upper third of the esophagus confirmed in 10 patients over 5 months.

Upper gastrointestinal exploration is carried out by a standard videoscope, under Propofol sedation, without specific coloring. HGM is approximately measured using the opening of the biopsy forceps. The diameter, color, location, and shape were described.

All endoscopic HGM lesions were confirmed by histopathological analysis of at least two biopsies of the endoscopic lesion. Systematic gastric biopsies were performed.

\section{Results}

736 patients underwent gastroscopy during the study period of 5 months, HGM of the proximal esophagus was 
discovered in 10 patients. They were 8 men (80\%) and 2 women (20\%) with an average age of 55 (range: 26 and 69). Two out of 10 patients were smoking (20\%) (Table 1).

\begin{tabular}{|c|c|}
\hline Table 1: Patient demographics. & \\
\hline Characteristic & HGM+ \\
\hline Male & 8 \\
\hline Female & 2 \\
\hline Male/female & 4 \\
\hline Age range (Year) & $26-69$ \\
\hline Mean age (Year) & 55 \\
\hline Smoking & 2 \\
\hline
\end{tabular}

Upper digestive endoscopy was requested for clinical manifestations of gastroesophageal reflux (GERD) in 8 patients $(80 \%)$. The other two indications were for iron deficiency (10\%) and looking for portal hypertension signs $(10 \%)$.

Clinical manifestations were dominated by dyspepsia (66\%) followed by epigastralgia (50\%), heartburn (33\%) and regurgitation (16\%) (Figure 1).

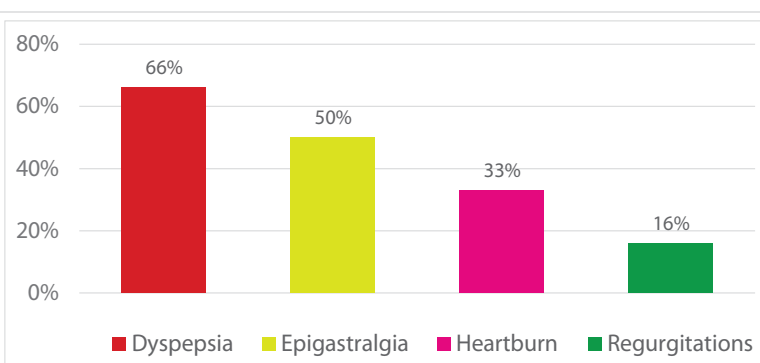

Figure 1: Clinical manifestations.

The endoscopic lesions associated with HGM were: Gastritis (70\%), hiatal hernia (10\%) without esophagitis or Brett's esophagus (Table 2).

Table 2: Endoscopic features in in patients with esophageal HGM.

\begin{tabular}{|c|c|}
\hline \multicolumn{2}{|c|}{ Esophageal HGM } \\
\hline Gastritis & $7(70 \%)$ \\
\hline Hiatal Hernia & $1(10 \%)$ \\
\hline Barett's esophagus & 0 \\
\hline Gastric Ulcer & 0 \\
\hline
\end{tabular}

The HGM lesions appear rounded, suspended, in salmonred color, well delimited, measuring on average $1.75 \mathrm{~cm}$ (extremes: 1.5 and $2 \mathrm{~cm}$ ), 2 in half of cases, sitting at $17.5 \mathrm{~cm}$ (range: 13 and $20 \mathrm{~cm}$ ) from dental arches (Figure 2).
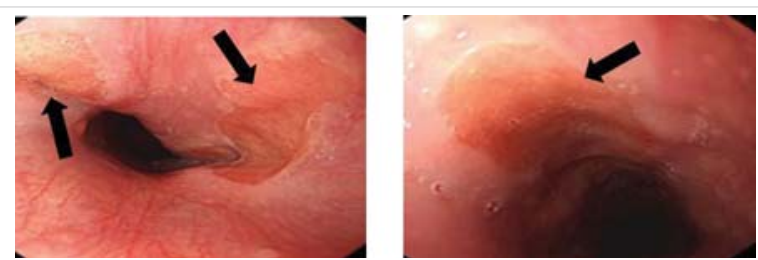

Figure 2: Endoscopic image of heterotopic gastric mucosa in proximal esophagus.
The histological study confirms the appearance of fundal glandular cells in all patient's biopsies (Figure 3), with intestinal metaplasia in $30 \%$ of cases within the HGM (Figure 4). Only one patient had Helicobacter pylori $(\mathrm{Hp}$ ) infection on the gastric tissue and HGM patch. No dysplasia was seen in the HGM (Table 3).

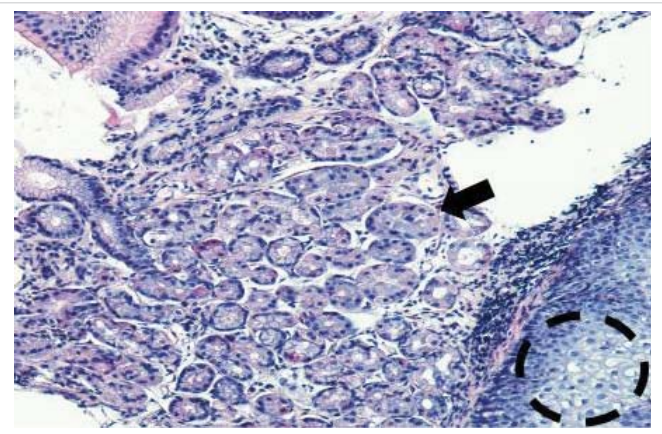

Figure 3: Microscopique examination shows the glandular fundic tissue (black arrow) with squamous epithelium down right (black circle) (H.E 40x).

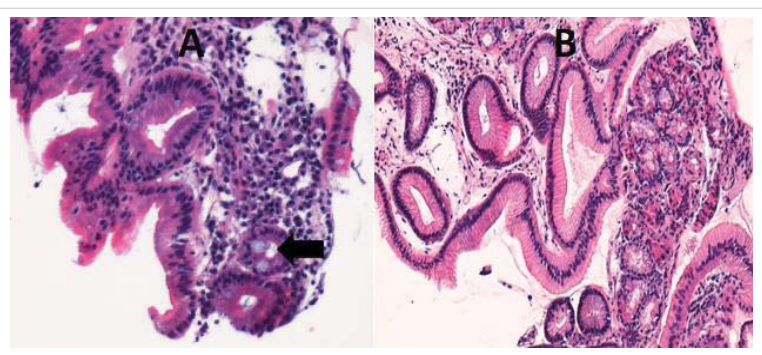

Figure 4: Microscopic examination shows in the same patient a draft of intestinal metaplasia (Arrow) (A) (HEx200) and glandular mucosa without metaplasia (B) (H.E. 100x)

Table 3: Histological appearance in patients with esophageal heterotopic gastric mucosa.

\begin{tabular}{|c|c|}
\hline \multicolumn{2}{|c|}{ Histological appearance } \\
\hline Chronic inflammation \\
\hline Positive & $7(70 \%)$ \\
\hline Negative & $3(30 \%)$ \\
\hline Intestinal metaplasia & $3(30 \%)$ \\
\hline Helicobacter Pylori & \\
\hline Positive & $1(10 \%)$ \\
\hline Negative & $9(90 \%)$ \\
\hline Dysplasia & 0 \\
\hline
\end{tabular}

\section{Discussion}

The most commonly accepted theory regarding the origin of esophageal HGM is the placement or sequestration of the gastric loop endoderm in the developing esophagus. This process is believed to occur at the embryonic stage of 4 weeks when the primitive stomach is located in the neck region. One study suggested that local differentiation or metaplasia of existing pluripotent cells could result in heterotopic gastric mucosa. However, it has also been hypothesized that entry plaques could develop in a multistage process from occluded esophageal glands located in the proximal esophagus leading to esophageal retention cysts, which could finally burst and lead to focal areas of the heterotopic gastric mucosa [1]. 
Another proposed theory involves the metaplastic transformation of the scaly mucosa exposed to chronic columnar acidity as seen in the Barett's esophagus. In histology, there will be a replacement of normal squamous epithelium of proximal esophagus by a metaplastic glandular mucosa due to the aggression induced by GERD: this is a phenomenon acquired [2].

The prevalence of HGM in this study $(1.3 \%)$ was at the lower end of reported prevalence in other studies $(0.1 \%$ 13.8\%) [3]. The detection rate of HGM was much higher in prospective endoscopic examinations of the upper gastrointestinal tract compared to the rate in retrospective analyses $[4,5]$. This lower rate could reflect the fact that our study was not prospective.

Endoscopic detection of esophageal HGM can be difficult due to its frequent location at or just below Killian's mouth, and as it is not considered a pre-neoplastic lesion, Like Barett's esophagus, HGM may not receive much attention from the operator. There may also be variations in endoscopic performance between practitioners [6].

Although the population studied did not experience any complications associated with HGM, it could be associated with serious consequences such as intestinal metaplasia, dysplasia, ulcers, fistulization and malignant transformation into adenocarcinoma $[7,8]$. Therefore, special attention should be given during endoscopy to investigate the possibility of HGM in the upper esophageal tract.

The higher prevalence of HGM in men compared to women in this study and in the literature [9-11] is unexplained. This difference may support the view that HGM is a congenital condition, but environmental factors as smoking or alcohol consumption in men may also be fact.

In our study, HGM may be associated with symptoms of the upper digestive tract, as in previously reported studies, although patients with this anomaly are most often asymptomatic.

The largest study to date was based on a database of 487,229 endoscopies, performed at non-referral centers in the United States. The results showed that dysphagia, odynophagia, globus, and respiratory symptoms were more common in patients with esophageal HGM than those without HGM [11].

No evidence is available to date on the relationship between acid secretion by the HGM of the cervical esophagus and its symptoms [12]. However, improvement in symptoms has been observed after the endoscopic treatment of HGM $[13,14]$.

The diagnosis of HGM of proximal esophagus is based on the endoscopic discovery of a salmon-colored area, distinct from the gastroesophageal junction and independent of Barrett's esophagus. The HGM is generally between 15 and $21 \mathrm{~cm}$ from the dental arches and is in the form of an ovoid or round velvety patch, pink or salmon. It is best to examine the proximal part of the esophagus when slowly removing the endoscope, with short, repeated insufflation when rotating the instrument clockwise or counterclockwise. The size of the patches varies from microscopic to $5 \mathrm{~cm}$ and can be single or multiple. Circumferential patches have been described. They are generally flat but may appear slightly depressed or raised, with a smooth or micronodular surface. Raised polyploid patches have rarely been described [15].

Many studies show that endoscopy with narrow band imaging (NBI) increases the detection rate of HGM patches by approximately three times compared to standard endoscopy at white light [16]. The NBI improves the detection of small lesions $(54 \%$ vs. $17 \%, p<0.0001$ in a prospective study of 99 patients with HGM of the cervical esophagus) [17]. It is recommended to confidently remove an input patch using virtual chromoendoscopy in light of this.

The histopathology of HGM is usually observed as fundictype, characterized by oxyntic features other than antral- or transitional-type [18], which is in accordance with the results of our study where all heterotopic patches were identified as fundic-type.

Dysplasia or adenocarcinoma was not observed in the study population. However, intestinal metaplasia, a potentially malignant condition, was present in three patients, this suggests that these are not infrequent events as reported in the literature [18]. HGM has been considered the soil for the development of benign and malignant tumors [19]. Since the first case reported by Carrie, et al. [20] in 1950, more than 40 cases of adenocarcinoma $[7,8]$ were reported in association with HGM. Therefore, intestinal metaplasia or dysplasia in patients with HGM may require monitoring.

Colonization of $H p$ in the HGM is considered to be part of positive $\mathrm{Hp}$ gastritis. No exclusive colonization of $\mathrm{Hp}$ in HGM has been reported. The reported frequency of $H p$ in esophageal HGM is very variable $(5.3 \%-73 \%)$ when bacteria are present in the stomach [21]. In our study, the $H p$ prevalence is $10 \%$.

The role of $H p$ inflammation in HGM is controversial; some studies in patients with a high frequency of bacteria $[22,23]$ have shown a correlation between inflammation and the presence of $\mathrm{H}$. pylori, but others $[24,25]$ have not.

Acid production and/or colonization of $\mathrm{Hp}$ in HGM patches can potentially lead to complications such as an esophageal ring, stenosis, ulcer, perforation or bleeding [26]. In our study, no such complication was observed in patients with MGH patches with or without $H p$ infection. 


\section{Therapeutic approach}

To determine the therapeutic strategy and the monitoring methods, a clinicopathological classification has been proposed (Table 4) [27].

\begin{tabular}{|c|c|}
\hline HGM I & Asymptomatic \\
\hline HGM II & Symptomatic without morphologic changes (dysphagia/ Odynophagia) \\
\hline HGM III & $\begin{array}{l}\text { Symptomatic with morphologic changes (benign complications: } \\
\text { strictures, ulcers, webs, stenosis, fistula) }\end{array}$ \\
\hline HGM IV & $\begin{array}{l}\text { Intraepithelial neoplasia (dysplasia) } \\
\text { (Low-grade/ high-grade) }\end{array}$ \\
\hline $\begin{array}{l}\text { HGM V } \\
\text { Suffix: } \\
\text { a } \\
\text { b }\end{array}$ & $\begin{array}{l}\text { Invasive adenocarcinoma } \\
\text { Inlet patch (Macroscopically visible patch of HGM) } \\
\text { Microscopic foci (Only microscopically visible HGM) }\end{array}$ \\
\hline
\end{tabular}

Asymptomatic patients (MGH I) do not require treatment.

Symptomatic patients (MGH II and MGH III) can benefit from first-line medical treatment, antihistamine type 2 and proton pump inhibitors are effective [28,29]. The multiple benign complications in the case of MGH III can be treated endoscopically but biopsies are essential to eliminate a malignant transformation.

In dysplasia (HGM IV), the therapeutic decision is difficult due to the rarity of reported cases. Some authors indicate endoscopic monitoring; others have proposed argon plasma coagulation (APC) or radiofrequency [30], despite the risk of complications; according to Dunn et al study including 10 symptomatic adult patients treated by radiofrequency, 8 patients presented histological and endoscopic remission of HGM after 2 sessions, without undesirable signs, with a clinical remission rate of $80 \%$. Klare, et al., treated 31 symptomatic adult patients with argon plasma coagulation: Resolution was achieved, with no evidence of adverse effects in 23 of the 31 patients treated [31]. The results of these two studies were good, hence the interest in standardizing therapeutic strategies according to good practice recommendations.

In the case of cancer, management is oncological. Due to the rarity of cases, Van Rahden proposed the same therapeutic strategy adopted in the case of squamous cell carcinoma of the cervical esophagus [27].

In our series two patients were asymptomatic classified I according to the clinicopathological classification (Table 4), they received no treatment. The other eight patients, classified II, received treatment with proton pump inhibitors with good clinical progress. All patients will benefit from endoscopic control.

\section{Conclusion}

HGM of proximal esophagus is a benign lesion discovered most often fortuitously by endoscopy. In our series, the prevalence is $1.3 \%$ with a clear male predominance. No case of dysplasia was identified.
In order not to ignore this anomaly, it is necessary to carry out a careful examination of the upper third of the esophagus at the withdrawal of the tube during any gastroscopy, to detect possible ranges of HGM and to do biopsies to confirm the diagnosis and look for possible dysplasia.

Due to insufficient data in the evolutionary literature, its management remains debated and could resemble that of Barett's esophagus for monitoring and therapeutic management, particularly in the event of symptoms or dysplasia.

\section{References}

1. Poyrazoglu OK, Bahcecioglu IH, Dagli AF, Ataseven $\mathrm{H}$, Celebi S, et al. Heterotopic gastric mucosa (inlet patch): endoscopic prevalence, histopathological, demographical and clinical characteristics. Int $J$ Clin Pract. 2009; 63: 287-291.

PubMed: https://www.ncbi.nlm.nih.gov/pubmed/17535303

2. Komori, Shuji, Shinji O, Yoshihiro T, Takao T, et al. A Case of Esophageal Adenocarcinoma Arising from the Ectopic Gastric Mucosa in the Thoracic Esophagus. Rare Tumors. 2010; 12-15.

PubMed: https://www.ncbi.nlm.nih.gov/pubmed/21139950

3. Yoshida T, Shimizu Y, Kato M. Image of the month. Use of magnifying endoscopy to identify early esophageal adenocarcinoma in ectopic gastric mucosa of the cervical esophagus. Clin Gastroenterol Hepatol. 2010; 8: e91-e93.

PubMed: https://www.ncbi.nlm.nih.gov/pubmed/20347051

4. Akanuma N, Hoshino I, Akutsu Y, Shuto K, Shiratori T, et al. Primary esophageal adenocarcinoma arising from heterotopic gastric mucosa: report of a case. Surg Today. 2013; 43: 446-451.

PubMed: https://www.ncbi.nlm.nih.gov/pubmed/22706784

5. Terada T. Heterotopic gastric mucosa of the gastrointestinal tract: a histopathologic study of 158 cases. Pathol Res Pract. 2011; 207: 148-150.

PubMed: https://www.ncbi.nlm.nih.gov/pubmed/21242038

6. Chen YR, Wu MM, Nan Q, Duan LP, Miao YL, et al. Heterotopic gastric mucosa in the upper and middle esophagus: 126 cases of gastroscope and clinical characteristics. Hepatogastroenterology. 2012; 59: 1123-1125.

PubMed: https://www.ncbi.nlm.nih.gov/pubmed/22580663

7. Neumann WL, Lujan GM, Genta RM. Gastric heterotopia in the proximal oesophagus ("inlet patch"): Association with adenocarcinomas arising in Barrett mucosa. Dig Liver Dis. 2012; 44: 292-296.

PubMed: https://www.ncbi.nlm.nih.gov/pubmed/22222950

8. Alagozlu H, Simsek Z, Unal S, Cindoruk M, Dumlu S, et al. Is there an association between Helicobacter pylori in the inlet patch and globus sensation? World J Gastroenterol. 2010; 16: 42-47. PubMed: https://www.ncbi.nlm.nih.gov/pubmed/20039447

9. Carrie A. Adenocarcinoma of the upper end of the oesophagus arising from ectopic gastric epithelium. Br J Surg. 1950; 37: 474. PubMed: https://www.ncbi.nlm.nih.gov/pubmed/15414304

10. Meining A, Bajbouj M, Preeg M, Reichenberger J, Kassem AM, et al. Argon plasma ablation of gastric inlet patches in the cervical esophagus may alleviate globus sensation: a pilot trial. Endoscopy. 2006; 38: 566-570.

PubMed: https://www.ncbi.nlm.nih.gov/pubmed/16802267

11. Latos W. Clinical evaluation of twenty cases of heterotopic gastric mucosa of upper esophagus during five-year observation, using gastroscopy in combination with histopathological and microbiological 
analysis of biopsies. Contemp Oncol. 2013; 17: 171-175.

PubMed: https://www.ncbi.nlm.nih.gov/pubmed/23788986

12. Von Rahden, et al. Heterotopic gastric mucosa of the esophagus literature-review and proposal of a clinicopathologic classification. Am J Gastroenterol. 2004; 99: 543-551.

PubMed: https://www.ncbi.nlm.nih.gov/pubmed/15056100

13. Mohammed IA, Streutker CJ, Ridell RH. Utilization of cytokeratins 7 and 20 does not differentiate between Barett's esophagus and gastric cardiac intestinal metaplasia. Mod Pathol. 2002; 15: 611-616.

14. Chatelain D, de Lajarte T. Adenocarcinoma of the upper esophagus arising in heterotopic gastric mucosa: Common pathogenesis with Barett's adenocarcinoma? Virchows Arch. 2002; 441: 406-411.

15. Klaase JM, Lemaire LC, Rauws EA. Heterotopic gastric mucosa of the cervical esophagus: A case of high-grade dysplasia treated with argon plasma coagulationand a case of adenocarcinoma. Gastrointest Endosc. 2001; 53: 101-104.

16. López CA. Prevalencia y características clínicas de pacientes con parche de mucosa gástrica ectópica en esófago Revista de Gastroenterología de México. 2019; 84: 442-448. PubMed:

17. Tang P, McKinley MJ, Sporrer M, Kahn E. Inlet patch: prevalence, histologic type, and association with esophagitis, Barrett esophagus, and antritis. Arch Pathol Lab Med. 2004; 128: 444-447.

PubMed: https://www.ncbi.nlm.nih.gov/pubmed/15043461

18. Borhan MF, Farnum JB. Incidence of heterotopic gastric mucosa in the upper oesophagus. Gut. 1991; 32: 968-972.

PubMed: https://www.ncbi.nlm.nih.gov/pubmed/1916499

19. Akbayir N, Alkim C, Erdem L, Sokmen HM, Sungun A, et al. Heterotopic gastric mucosa in the cervical esophagus (inlet patch): endoscopic prevalence, histological and clinical characteristics. J Gastroenterol Hepatol. 2004; 19: 891-896.

PubMed: https://www.ncbi.nlm.nih.gov/pubmed/15242492

20. Bajbouj M, Becker V, Eckel F, Miehlke S, Pech O, et al. Argon plasma coagulation of cervical heterotopic gastric mucosa as an alternative treatment for globus sensations. Gastroenterology 2009; 137: 440444.

PubMed: https://www.ncbi.nlm.nih.gov/pubmed/19410576

21. Dunn JM, Sui G, Anggiansah A, et al. Radiofrequency ablation of symptomatic cervical inlet patch using a through-the-scope device: a pilot study. Gastrointest Endosc. 2016; 84: 1022-1026.

PubMed: https://www.ncbi.nlm.nih.gov/pubmed/27373671
22. Rusu R. Cervical inlet patch: new insights into diagnosis and endoscopic therapy. Frontline Gastroenterology. 2017; 0: 1-7. PubMed: https://www.ncbi.nlm.nih.gov/pubmed/30046427

23. Al-Mammari S, Selvarajah U, East JE. Narrow band imaging facilitates detection of inlet patches in the cervical oesophagus. Dig Liver Dis. 2014; 46: 716-719.

PubMed: https://www.ncbi.nlm.nih.gov/pubmed/24890619

24. Cheng CL, Lin CH, Liu NJ. Endoscopic diagnosis of cervical esophageal heterotopic gastric mucosa with conventional and narrow-band images. World J Gastroenterol. 2014; 20: 242-249. PubMed: https://www.ncbi.nlm.nih.gov/pubmed/24415878

25. Yu Fang. Prevalence, histologic and clinical characteristics of heterotopic gastric mucosa in Chinese patients. World $\mathrm{J}$ Gastroenterol. 2014; 20: 17588-17594.

PubMed: https://www.ncbi.nlm.nih.gov/pubmed/25516674

26. Ohara M. Incidence of heteroptopic gastric mucosa in the upper esophagus in first time narrow banding image endoscopy of consecutive 900 patients. Gastrointest Endosc. 2010; 71: 316-317.

27. Azar C, Jamali F, Tamim H, Abdul-Baki H, Soweid A. Prevalence of endoscopically identified heterotopic gastric mucosa in the proximal esophagus: endoscopist dependent? J Clin Gastroenterol. 2007; 41: 468-471.

PubMed: https://www.ncbi.nlm.nih.gov/pubmed/17450028

28. Gutierrez O, Akamatsu T, Cardona H, Graham DY, El-Zimaity HM. Helicobacter pylori and heterotopic gastric mucosa in the upper esophagus (the inlet patch). Am J Gastroenterol. 2003; 98: 12661270.

29. Jacobs E, Dehou MF. Heterotopic gastric mucosa in the upper esophagus: a prospective study of 33 cases and review of literature. Endoscopy. 1997; 29: 710-715.

PubMed: https://www.ncbi.nlm.nih.gov/pubmed/9427488

30. Galan AR, Katzka DA, Castell DO. Acid secretion from an esophageal inlet patch demonstrated by ambulatory $\mathrm{pH}$ monitoring. Gastroenterology. 1998; 115: 1574-1576.

PubMed: https://www.ncbi.nlm.nih.gov/pubmed/9834287

31. Meining A, Bajbouj M. Gastric Inlet Patches in The cervical esophagus: what they are, what they cause and how they can be treated. Gastrointestinal Endoscopy. 2016; 84: 1027-1029.

PubMed: https://www.ncbi.nlm.nih.gov/pubmed/27855791 